\title{
Experience of stigma by people with schizophrenia compared with people with depression or malignancies
}

\author{
Piotr Świtaj, ${ }^{1}$ Jacek Wciórka, ${ }^{1}$ Paweł Grygiel, ${ }^{2}$ Julita Smolarska-Świtaj, ${ }^{3}$ Marta Anczewska, \\ Artur Grzesik ${ }^{4}$
}

The Psychiatrist (2011), 35, 135-139, doi: 10.1192/pb.bp.110.029579

\begin{abstract}
${ }^{1}$ Institute of Psychiatry and Neurology Warsaw, Poland; ${ }^{2}$ Institute of Sociology, University of Rzeszów Rzeszów, Poland; ${ }^{3}$ Department of Cardiology, Public Central Teaching Hospital, Warsaw, Poland; ${ }^{4}$ Faculty of Management, Rzeszów University of Technology, Rzeszów, Poland Correspondence to Piotr Świtaj (switaj@ipin.edu.pl)

First received 14 Jan 2010, final revision 30 Aug 2010, accepted 5 Nov 2010
\end{abstract}

Aims and method To compare the frequency of experiences of stigma reported by people with schizophrenia and by people with other health problems (depression and malignancies). The Stigma section of the Consumer Experiences of Stigma Questionnaire (CESQ) was administered to 153 people with schizophrenia, 106 people with depression and 85 people with malignancies.

Results Using multiple regression analysis we showed that after controlling for the differences in the participants' background characteristics, people with depression did not differ significantly in terms of the frequency of self-reported stigma experiences from patients with schizophrenia $(\beta=-0.064, P>0.05)$. However, patients with malignancies felt stigmatised significantly less often than patients with schizophrenia $(\beta=-0.240, P<0.05)$.

Clinical implications Our findings confirm that the stigma of mental illness is more pronounced than the stigma associated with physical health problems. Contrary to expectations, however, we were not able to demonstrate that people with depression are treated more favourably and experience less stigma than people with schizophrenia.

Declaration of interest None.
The term 'stigma' was popularised in the social sciences by Erving Goffman, ${ }^{1}$ who used it to refer to 'an attribute that is deeply discrediting'. The author noticed, however, that 'a language of relationships, not attributes is really needed' and he emphasised the dynamic process of the social construction of stigma. Strictly speaking, in Goffman's formulation, stigma 'is really a special kind of relationship between attribute and stereotype'. For practical reasons, however, Goffman often spoke about stigma as if it were an attribute, because there are important attributes that are discrediting in all contexts. One typical example is mental illness. Although societal reactions to some attributes, such as obesity, show substantial variability across time and across cultures, mental illness seems to be associated with a stigma that is universal and less dependent on historical or cultural contingencies. ${ }^{2}$ The review of the studies conducted in recent years confirms unequivocally that stigmatisation of people receiving psychiatric treatment is a common, transcultural phenomenon, and mental illness is still a strong socially excluding condition. ${ }^{3-5}$ A large body of research indicates that stigma may exert numerous detrimental effects on people with mental disorders, limiting their life opportunities and leading to diminished self-esteem and self-efficacy, compromised quality of life and non-adherence to treatment. ${ }^{3,6}$
One of the most disabling and severely stigmatised mental disorders is schizophrenia, which was selected as the central focus of the World Psychiatric Association's global anti-stigma programme 'Open the Doors'. However, insufficient effort has been made so far to study the issue of subjective experience of stigmatisation among people with schizophrenia. Two large international studies aiming to fill this gap in research have been conducted and demonstrated that significant proportions of people with schizophrenia anticipate, actually experience and internalise stigma. 8

It seems, in particular, that the scope and nature of actual stigma experienced by people with schizophrenia is still understudied. Additionally, in this kind of research, a variety of non-standardised instruments have been used to measure self-reported stigmatisation, which makes comparisons of the obtained results difficult. The interpretation of these findings often poses significant problems, because it is hard to define what rates of experienced stigma should be regarded as high. A partial solution to this difficulty could be a comparison of the extent of stigma reported by people with schizophrenia and by people with other mental disorders or by people belonging to other potentially stigmatised groups. One of the possible points of reference for people receiving psychiatric treatment is 
people with physical illnesses. Such a research strategy would enable the more reliable assessment of the relative strength of the stigma linked to schizophrenia, by putting the results in some context. Unfortunately, studies comparing the experiences of patients with different psychiatric diagnoses (e.g. Lai et al, ${ }^{10}$ Angermeyer et $a l^{1 \mathrm{l}}$ ) and studies comparing the experiences of patients with schizophrenia and patients with physical illnesses (e.g. Lai et $a l,{ }^{10}$ Lee $e t a l^{12}$ ) are relatively rare.

In another study we attempted to establish the extent of stigma experienced by people with schizophrenia and tried to determine its sociodemographic and clinical correlates. ${ }^{13}$ In this paper we seek to expand on our earlier findings by comparing the rates of stigmatisation reported by our sample of people with schizophrenia and by people with other health problems. For this purpose, we recruited two groups of respondents - people with depression and people with malignancies. Depression was selected because it is, similarly to schizophrenia, a common and severe mental disorder; however, depression is usually viewed by the public more benignly than schizophrenia. ${ }^{5}$ We wanted to test whether this difference in societal attitudes translates into a difference in the subjective experience of people with psychiatric disorders. Malignancies were chosen because some evidence exists that they may carry social stigma $^{14}$ and they have already been used as controls in previous studies of the stigma associated with mental disorders (e.g. Corrigan et $a l^{15}$ ).

\section{Method}

\section{Participants}

For group 1, people with schizophrenia were recruited from psychiatric in-patient wards of the Institute of Psychiatry and Neurology (IPiN) and from one of the public psychiatric out-patient clinics in Warsaw. Participation in the study was offered to all consecutive patients who attended the outpatient clinic or who were admitted to in-patient wards and met the following criteria: diagnosed with schizophrenia according to $\mathrm{ICD}-10^{16}$ criteria (F20); aged 18-65 years; not dependent on drugs or alcohol; and in a stable mental state according to their attending psychiatrist. Of 177 people screened as eligible for the study, $153(86.4 \%)$ agreed to participate and provided informed consent. The final sample consisted of 62 out-patients $(40.5 \%)$ and 91 in-patients (59.5\%).

For group 2, people with depression were recruited from psychiatric in-patient wards, a day centre, an outpatient clinic at the IPiN, and the same public psychiatric out-patient clinic as for the people with schizophrenia. This group consisted of people with an ICD-10 diagnosis of depressive episode (F32) or recurrent depressive disorder (F33), ${ }^{16}$ without comorbid substance dependence and whose mental state at the time of evaluation was stable, allowing the relevant information to be obtained. Of the 118 consecutive patients who fulfilled the inclusion criteria, 106 (89.8\%) agreed to participate in the study. The final sample included 64 out-patients or day patients (60.4\%) and 42 in-patients (39.6\%).
For group 3, patients with malignancies were recruited at the Department of Hematology, Oncology and Internal Medicine of the Public Central Teaching Hospital in Warsaw and at two oncology centres in Rzeszów, a city in south-eastern Poland. Altogether, 85 consecutive patients agreed to participate. The refusal rate was less than $20 \%$. The participants' diagnoses included haematological malignancies or some form of cancer.

The background characteristics of the participants are presented in Table 1. As could be expected, the groups differed significantly in their background characteristics. The differences found between the groups seem to result from the nature of the participants' health problems.

\section{Instrument}

The extent of experienced stigmatisation was assessed using the Stigma section of the Consumer Experiences of Stigma Questionnaire (CESQ). ${ }^{17}$ This part of the questionnaire includes nine items concerning people's experiences as patients with psychiatric disorders. The Polish version of the CESQ has been modified slightly from the original version for the purpose of this study. The term 'consumers' was substituted with the term 'people receiving psychiatric treatment' (or 'I receive psychiatric treatment', where appropriate). Appropriate changes in wording were also made to the questionnaire administered to people with malignancies. The responses to the questionnaire statements are scored on a five-point scale that describes the frequency of each stigma experience, ranging from 1 'never' to 5 - 'very often'. Two questionnaire items referring to positive interpersonal experiences are reversely coded. The mean scores for each item and for the entire scale have been calculated, with higher ratings indicating more frequent stigma experiences. In our sample the questionnaire showed adequate internal consistency (Cronbach's $\alpha=0.82$ ).

\section{Procedures}

Ethical approval of the present study was granted by the Bioethical Committee at IPiN. Patients were invited to participate by one of the researchers during their stay in a ward or in a waiting room of an out-patient clinic. In some cases, the attending clinicians were also involved in the recruitment procedure. All participants provided their informed consent. Clinical and sociodemographic information was gathered from interviews with the participants and from their medical records. The CESQ was administered as an interview.

\section{Statistics}

Data were analysed using PASW Statistics 18.0 for Windows. The participants' background characteristics were compared with $\chi^{2}$ and analysis of variance (ANOVA) tests, where appropriate. The effect of diagnosis on the frequency of reported stigma experiences was assessed using multiple regression models. $P$-values less than 0.05 were considered to be statistically significant. 


\begin{tabular}{|c|c|c|c|c|}
\hline Characteristic & $\begin{array}{l}\text { Schizophrenia group } \\
(n=153)\end{array}$ & $\begin{array}{l}\text { Depression group } \\
\quad(n=106)\end{array}$ & $\begin{array}{l}\text { Malignancies group } \\
\qquad(n=85)\end{array}$ & $\begin{array}{c}\text { Group comparison } \\
P\end{array}$ \\
\hline Gender, \% female & 51.6 & 72.6 & 58.8 & $0.003^{a}$ \\
\hline Age, years: mean (s.d.) & $42.5(12.6)$ & $56.0(12.2)$ & $55.8(12.2)$ & $<0.001^{b}$ \\
\hline $\begin{array}{l}\text { Marital status, \% } \\
\text { Married } \\
\text { Unmarried }\end{array}$ & $\begin{array}{l}20.3 \\
79.7 \\
\end{array}$ & $\begin{array}{l}59.4 \\
40.6 \\
\end{array}$ & $\begin{array}{l}77.6 \\
22.4 \\
\end{array}$ & $<0.001^{a}$ \\
\hline $\begin{array}{l}\text { Education, \% } \\
\text { Primary or vocational } \\
\text { Secondary or higher } \\
\end{array}$ & $\begin{array}{l}30.1 \\
69.9 \\
\end{array}$ & $\begin{array}{l}18.9 \\
81.1\end{array}$ & $\begin{array}{l}42.4 \\
57.6 \\
\end{array}$ & $0.002^{a}$ \\
\hline $\begin{array}{l}\text { Place of residence, } \% \\
\text { Village or town (population <100 000) } \\
\text { City (population >100000) }\end{array}$ & $\begin{array}{l}11.1 \\
88.9\end{array}$ & $\begin{array}{l}24.5 \\
75.5\end{array}$ & $\begin{array}{l}76.5 \\
23.5\end{array}$ & $<0.001^{a}$ \\
\hline $\begin{array}{l}\text { Living situation, \% } \\
\text { Living independently } \\
\text { Not living independently }\end{array}$ & $\begin{array}{l}52.9 \\
47.1\end{array}$ & $\begin{array}{r}94.3 \\
5.7 \\
\end{array}$ & $\begin{array}{r}92.9 \\
7.1 \\
\end{array}$ & $<0.001^{a}$ \\
\hline $\begin{array}{l}\text { Employment status, \% } \\
\text { Employed } \\
\text { Unemployed } \\
\end{array}$ & $\begin{array}{l}18.3 \\
81.7\end{array}$ & $\begin{array}{l}32.1 \\
67.9 \\
\end{array}$ & $\begin{array}{l}29.4 \\
70.6 \\
\end{array}$ & $0.026^{a}$ \\
\hline Duration of illness, years: mean (s.d.) & $17.3(11.2)$ & $11.2(9.8)$ & $1.5(3.1)$ & $<0.001^{b}$ \\
\hline
\end{tabular}

a. $\chi^{2}$-tests.

b. Analysis of variance (ANOVA) tests.

\begin{tabular}{|c|c|c|c|}
\hline CESQ item $^{\mathrm{b}}$ & $\begin{array}{l}\text { Schizophrenia } \\
\text { Mean (s.d.) } \\
(n=153)\end{array}$ & $\begin{array}{l}\text { Depression } \\
\text { Mean (s.d.) } \\
(n=106)\end{array}$ & $\begin{array}{l}\text { Malignancies } \\
\text { Mean (s.d.) } \\
(n=85)\end{array}$ \\
\hline $\begin{array}{l}\text { 1. I have avoided telling others outside my immediate family that I have received } \\
\text { psychiatric treatment (I have received treatment for malignancy) }\end{array}$ & $3.8(1.2)$ & $3.5(1.5)$ & $2.4(1.3)$ \\
\hline $\begin{array}{l}\text { 2. I have been treated as less competent by others when they learned I had received } \\
\text { psychiatric treatment (I had received treatment for malignancy) }\end{array}$ & $2.9(1.4)$ & $2.2(1.4)$ & $2.5(1.1)$ \\
\hline $\begin{array}{l}\text { 3. Friends who learned that I received psychiatric treatment (I received treatment for } \\
\text { malignancy) have been supportive and understanding }\end{array}$ & $2.6(1.2)$ & $2.4(1.4)$ & $2.1(1.3)$ \\
\hline $\begin{array}{l}\text { 4. I have been shunned or avoided when it was revealed that I received psychiatric } \\
\text { treatment (I received treatment for malignancy) }\end{array}$ & $2.3(1.4)$ & $1.9(1.3)$ & $1.8(0.9)$ \\
\hline $\begin{array}{l}\text { 5. I have been in situations where I have heard others say unfavourable or offensive } \\
\text { things about people receiving psychiatric treatment (about people receiving } \\
\text { treatment for malignancies) and their illnesses }\end{array}$ & $3.2(1.3)$ & $3.0(1.3)$ & $1.8(1.0)$ \\
\hline $\begin{array}{l}\text { 6. I have been advised to lower my expectations in life because I receive psychiatric } \\
\text { treatment (I receive treatment for malignancy) }\end{array}$ & $2.3(1.4)$ & $1.9(1.3)$ & $2.1(1.2)$ \\
\hline $\begin{array}{l}\text { 7. I have been treated fairly by others who knew that I received psychiatric treatment } \\
\text { (I received treatment for malignancy) }\end{array}$ & $2.4(1.0)$ & $1.9(1.1)$ & $2.1(1.1)$ \\
\hline $\begin{array}{l}\text { 8. I have seen or read things in the mass media about people receiving psychiatric } \\
\text { treatment (about people receiving treatment for malignancies) that I find hurtful or } \\
\text { offensive }\end{array}$ & $2.4(1.3)$ & $2.3(1.1)$ & $1.8(1.0)$ \\
\hline $\begin{array}{l}\text { 9. I have worried that others will view me unfavourably because I received psychiatric } \\
\text { treatment (I received treatment for malignancy) }\end{array}$ & $2.9(1.4)$ & $2.3(1.4)$ & $1.8(1.1)$ \\
\hline Total scale score & $2.7(0.8)$ & $2.4(0.9)$ & $2.0(0.7)$ \\
\hline
\end{tabular}

a. Response categories: 1 , never; 2 , seldom; 3 , sometimes; 4, often; 5, very often.

b. Items 3 and 7, which refer to positive interpersonal experiences, are reversely coded. Higher scores always indicate more frequent stigma experiences.

\section{Results}

Table 2 presents the mean scores obtained by the participants on the CESQ. As can be seen, respondents with schizophrenia and respondents with depression scored highest (between 3 - 'sometimes' and 4 - 'often') on item 1 regarding concealing one's illness outside the immediate family and item 5 referring to overhearing people making negative comments about mental illness. Patients with malignancies on all CESQ items obtained scores below the midpoint of the scale (3 - 'sometimes').

To assess the effect of diagnosis on the extent of stigmatisation, multiple regression analysis was carried out. In the first model, only two binary variables related to the 
Table 3 Summary of multiple regression analysis for variables predicting experienced stigmatisation $(N=344)$

\begin{tabular}{|c|c|c|c|}
\hline Variable & $B$ & s.e. $B$ & $\beta$ \\
\hline \multicolumn{4}{|l|}{ Model $1^{a}$} \\
\hline Depression (ref. schizophrenia) & -0.358 & 0.099 & $-0.200^{* * *}$ \\
\hline Malignancies (ref. schizophrenia) & -0.710 & 0.105 & $-0.370^{* * *}$ \\
\hline \multicolumn{4}{|l|}{ Model $2^{b}$} \\
\hline Depression (ref. schizophrenia) & -0.114 & 0.132 & -0.064 \\
\hline Malignancies (ref. schizophrenia) & -0.460 & 0.184 & $-0.240^{*}$ \\
\hline Gender $(1$, male; 0 , female $)$ & 0.068 & 0.088 & 0.040 \\
\hline Age, years & -0.011 & 0.004 & $-0.189^{\star \star}$ \\
\hline Marital status (1, married; 0 , unmarried) & -0.167 & 0.099 & -0.100 \\
\hline Education ( 1 , secondary or higher; 0 , primary or vocational) & 0.072 & 0.093 & 0.040 \\
\hline Place of residence ( 1 , city: population $>100000$; 0 , village or town: population $<100000$ ) & -0.187 & 0.112 & -0.105 \\
\hline Living situation ( 1 , not living independently; 0 , living independently) & 0.234 & 0.127 & 0.121 \\
\hline Employment status ( 1 , employed; 0 , unemployed) & 0.001 & 0.101 & 0.000 \\
\hline Duration of illness, years & 0.014 & 0.005 & $0.184^{\star \star}$ \\
\hline
\end{tabular}

ref., reference.

Model 1: $R^{2}=0.120, F$ change $(2,341)=23.301, P<0.001$

b. Model 2: $R^{2}=0.181, F$ change $(8,333)=3.066, P=0.002$

${ }^{\star} P<0.05 ;{ }^{* \star} P<0.01 ;{ }^{* \star \star} P<0.001$.

diagnosis were entered into the regression equation: depression and malignancies (people with schizophrenia were treated as the reference group). As shown in Table 3, this model accounted for $12 \%$ of the variation in experienced stigma. The values of the regression coefficients indicate that people with depression and people with malignancies experienced significantly less stigmatisation than people with schizophrenia.

In the second model, the following background characteristics of the participants were entered into the regression equation as control variables: gender, age, marital status, education, place of residence, living situation, employment status and duration of illness. As can be seen in Table 3, this model accounted for $18.1 \%$ of the variance in stigma. Two of the eight control variables were significantly related to the level of experienced stigmatisation: age and duration of illness. Respondents who were younger or who had a longer duration of illness reported more frequent stigma experiences. After controlling for participants' background characteristics, people with schizophrenia still had significantly higher stigma levels than people with malignancies, whereas the difference between people with schizophrenia and people with depression was no longer significant.

\section{Discussion}

The purpose of this study was to assess the extent of stigma experienced by people with schizophrenia compared with people with depression and people with malignancies. On the basis of the review of the studies of public beliefs and attitudes, we could expect people with depression to report less stigmatisation than people with schizophrenia. ${ }^{5}$ Surprisingly, after controlling for the participants' background characteristics, we did not find significant differences in the frequency of stigmatisation between the two groups. Possibly our samples were too small to detect existing differences, but we cannot exclude the possibility that people with different severe mental disorders in reallife situations are the objects of non-specific stereotyping and prejudice. Perhaps social responses to various types of mental disorder, which seem to differ in the artificial circumstances where the stimulus is simply a label or a vignette, become more standardised in situations of actual contact with people receiving psychiatric treatment.

Another explanation for our unexpected finding can also be taken into account. In one previous study it was found that people with schizophrenia reported concrete stigmatisation experiences more frequently than people with depression, but both groups anticipated stigmatisation similarly frequently. ${ }^{11}$ In this context, it should be noted that although the main focus of the CESQ is on actual stigmatisation, two of its items refer to people's behavioural (avoidance of disclosure) or emotional (worrying) reactions to stigma resulting from anticipating social disapproval rather than to concrete stigma experiences. Furthermore, another two CESQ items ask about instances of what Wahl calls 'indirect' stigmatisation (i.e. not targeting the respondents directly but reflective of the stereotypes and prejudice widespread in society), ${ }^{17}$ such as offensive media content or negative comments about people with mental illnesses. When responding to these items, participants probably did not differentiate between various psychiatric diagnoses but had in mind mental health service users in general. It may be the case then that people with schizophrenia and people with depression differ only in some aspects of the subjective experience of stigma (e.g. experiences of direct stigmatisation, but not anticipated or indirect stigmatisation), and instruments assessing these various constructs more specifically than the CESQ are needed to capture these differences.

Instead, the comparison of the strength of the stigma of schizophrenia and the stigma associated with malignancies in our study yielded results concordant with our expectations. In this respect our findings confirm what is well known from the literature on the nature of social stigma, which clearly reveals that although physical disability or somatic illness may be a cause of rejection, ${ }^{18}$ it is usually less pronounced than in the case of mental disorders (e.g. Lai et $a l,{ }^{10}$ Lee et $a l,{ }^{12}$ Corrigan et $a l^{15}$ Tringo $\left.{ }^{19}\right)$. 
This study has several limitations. The generalisability of our results should be made with caution because our participants were not selected randomly and came from just a few healthcare institutions in only two cities, so they may not be representative of the entire populations of people with schizophrenia, people with depression and people with malignancies in Poland. Furthermore, although our main sample was quite large, the size of the comparison groups was smaller, which reduces the statistical power of the between-group comparisons. We did not control for important factors such as between-group differences in the severity of symptoms, level of disability or intensity of service use. Finally, we cannot rule out that some of the respondents, apart from their main illnesses, had other psychiatric or somatic health problems that could contribute to their perception of being stigmatised.

Despite of these limitations, we believe that the present findings shed a little more light on the issue of the extent of stigma experienced by people with schizophrenia. Further research should explore in detail specific areas in which people with a diagnosis of schizophrenia are more likely to be stigmatised than people with other health conditions.

\section{Funding}

This study was supported by a grant from the Polish Ministry of Science and Higher Education (2 PO5D 102 29).

\section{About the authors}

Piotr Świtaj is a psychiatrist and JacekWciórka is Professor of Psychiatry at the Institute of Psychiatry and Neurology, Warsaw, Poland. Pawel Grygiel is a sociologist at the Institute of Sociology, University of Rzeszów, Rzeszów, Poland. Julita Smolarska-Świtaj is a trainee in internal medicine at the Department of Cardiology, Public Central Teaching Hospital, Warsaw, Poland. Marta Anczewska is a psychiatrist at the Institute of Psychiatry and Neurology, Warsaw, Poland. Artur Grzesik is a sociologist at the Faculty of Management, Rzeszów University of Technology, Rzeszów, Poland.

\section{References}

1 Goffman E. Stigma: Notes on the Management of Spoiled Identity. Penguin, 1968.

2 Stangor C, Crandall CS. Threat and the social construction of stigma. In The Social Psychology of Stigma (eds TF Heatherton, RE Kleck, MR Hebl, JG Hull): 62-87. Guilford Press, 2000.
3 Farina A. Stigma. In Handbook of Social Functioning in Schizophrenia (eds KT Mueser, N Tarrier): 247-79. Allyn \& Bacon, 1998.

4 Lee S. The stigma of schizophrenia: a transcultural problem. Curr Opin Psychiatry 2002; 15: 37-41.

5 Angermeyer MC, Dietrich S. Public beliefs about and attitudes towards people with mental illness: a review of population studies. Acta Psychiatr Scand 2006; 113: 163-79.

6 Corrigan PW, Kleinlein P. The impact of mental illness stigma. In On the Stigma of Mental Illness: Practical Strategies for Research and Social Change (ed PW Corrigan): 11-44. American Psychological Association, 2005.

7 Sartorius N, Schulze H. Reducing the Stigma of Mental Illness: A Report from a Global Programme of the World Psychiatric Association. Cambridge University Press, 2005.

8 Thornicroft G, Brohan E, Rose D, Sartorius N, Leese M. Global pattern of experienced and anticipated discrimination against people with schizophrenia: a cross-sectional survey. Lancet 2009; 373: 408-15.

9 Brohan E, Elgie R, Sartorius N, Thornicroft G. Self-stigma, empowerment and perceived discrimination among people with schizophrenia in 14 European countries: the GAMIAN-Europe Study. Schizophr Res 2010; 122: $232-8$.

10 Lai YM, Hong CPH, Chee CYI. Stigma of mental illness. Singapore Med J 2000; 42: 111-4.

11 Angermeyer MC, Beck M, Dietrich S, Holzinger A. The stigma of mental illness: patients' anticipations and experiences. Int J Soc Psychiatry 2004; 50: 153-62.

12 Lee S, Lee MTY, Chiu MYL, Kleinman A. Experience of social stigma by people with schizophrenia in Hong Kong. Br J Psychiatry 2005; 186 $153-7$.

13 Świtaj P, Wciórka J, Smolarska-Świtaj J, Grygiel P. Extent and predictors of stigma experienced by patients with schizophrenia. Eur Psychiatry 2009; 24: 513-20.

14 Fife BL, Wright ER. The dimensionality of stigma: a comparison of its impact on the self of persons with HIV/AIDS and cancer. $J$ Health Soc Behav 2000; 41: 50-67.

15 Corrigan PW, Lurie BD, Goldman HH, Slopen N, Medasani K, Phelan S. How adolescents perceive the stigma of mental illness and alcohol abuse. Psychiatr Serv 2005; 56: 544-50.

16 World Health Organization. The ICD-10 Classification of Mental and Behavioural Disorders: Clinical Descriptions and Diagnostic Guidelines. WHO, 1992

17 Wahl OF. Mental health consumers' experience of stigma. Schizophr Bull 1999; 25: 467-78.

18 Mason T, Carlisle C, Watkins C, Whitehead E (eds). Stigma and Socia Exclusion In Healthcare. Routledge, 2001.

19 Tringo JL. The hierarchy of preference toward disability groups. J Spec Educ 1970; 4: 295-306. 